\title{
Cost of End-of-Life Inpatient Encounters in Patients with Chronic Kidney Disease in the United States: A Report from the DISCOVER CKD Retrospective Cohort
}

\author{
Carol Pollock (1) - Glen James (D) - Juan Jose Garcia Sanchez • \\ Matthew Arnold · Juan-Jesus Carrero - Carolyn S. P. Lam • \\ Hungta Chen $\cdot$ Stephen Nolan $\cdot$ Roberto Pecoits-Filho
}

Received: September 30, 2021 / Accepted: November 30, 2021 / Published online: February 3, 2022

(C) The Author(s) 2022

\section{ABSTRACT \\ Introduction: Real-world data reporting healthcare resource utilisation and costs asso- ciated with end-of-life care for patients with chronic kidney disease (CKD) are limited. We}

Supplementary Information The online version contains supplementary material available at https:// doi.org/10.1007/s12325-021-02010-3.

\author{
C. Pollock $(\bowtie)$ \\ Kolling institute, Royal North Shore Hospital, \\ University of Sydney, Sydney, NSW 2065, Australia \\ e-mail: carol.pollock@sydney.edu.au \\ G. James · J. J. Garcia Sanchez · M. Arnold · S. Nolan \\ BioPharmaceuticals Business Unit, AstraZeneca, \\ Cambridge, UK \\ G. James \\ e-mail: glen-jamesphd@hotmail.com \\ J. J. Garcia Sanchez \\ e-mail: juanjose.garciasanchez@astrazeneca.com \\ M. Arnold \\ e-mail: matthew.arnold2@astrazeneca.com \\ S. Nolan \\ e-mail: stephen.nolan@astrazeneca.com

\section{J.-J. Carrero} \\ Department of Medical Epidemiology and \\ Biostatistics, Karolinska Institutet, Stockholm, \\ Sweden \\ e-mail: juan.jesus.carrero@ki.se
}

examined length of hospitalisation and costs associated with end-of-life inpatient encounters using retrospective data from DISCOVER CKD. Methods: Data on inpatient encounters for patients with $\mathrm{CKD}$ aged $\geq 18$ years between January 2016 and March 2020 were extracted from the US Premier Hospital Database. Encounters ending in death were identified and grouped by reason for the encounter, using the International Classification of Diseases, Tenth Revision, and by their insurance coverage.

C. S. P. Lam

Department of Cardiology, National Heart Centre, Singapore, Singapore

\section{S. P. Lam}

Duke-NUS Medical School, Singapore, Singapore e-mail: carolyn.lam@duke-nus.edu.sg

\section{H. Chen}

BioPharmaceuticals Business Unit, AstraZeneca, Gaithersburg, MD, USA

e-mail: hungta.chen@astrazeneca.com

R. Pecoits-Filho

School of Medicine, Pontifical Catholic University of Parana, Curitiba, Brazil

R. Pecoits-Filho

Arbor Research Collaborative for Health, Ann Arbor, MI, USA

e-mail: r.pecoits@pucpr.br 
Encounters were evaluated overall and stratified according to cardiovascular (CV), kidney failure and infection-related reasons, and by their coverage by commercial, Medicaid, Medicare or other insurers. Length of hospitalisation and total costs were calculated for encounters.

Results: Among 237,734 encounters ending in death, the mean [standard deviation (SD)] age was 74.2 (12.4) years, and $45.3 \%$ of patients were female. In total, 25,118, 4210 and 76,307 encounters were classified as relating to $\mathrm{CV}$ reasons, kidney failure and infection, respectively. Among all encounters, the mean (SD) length of hospitalisation ranged from 9.1 (11.2) (Medicare) to 12.8 (18.4) (Medicaid) days. Across insurers, encounters related to kidney failure were associated with the longest hospitalisations compared with $\mathrm{CV}$ and infection [mean range (days): $10.7-15.9$ vs. $7.5-10.5$ and 8.7-12.7, respectively]. The median [interquartile range (IQR)] total cost of any inpatient encounter was \$17,057 (\$8040-35,873). Kidney failure-related encounters had higher costs compared with $\mathrm{CV}$ and infection [median (IQR), \$18,469 (\$8673-38,315) vs. \$17,503 $(\$ 7766-39,693)$ and $\$ 16,403$ (\$7762-34,910), respectively]. Medicaid-covered encounters had the highest costs of all insurers [median (IQR), \$16,189 (\$7725-33,443)].

Conclusions: Among patients with CKD, endof-life encounters were most frequently related to infection. Encounters relating to kidney failure incurred the highest costs.

Trial registration: ClinicalTrials.gov identifier: NCT04034992. 


\section{Graphical Abstract}

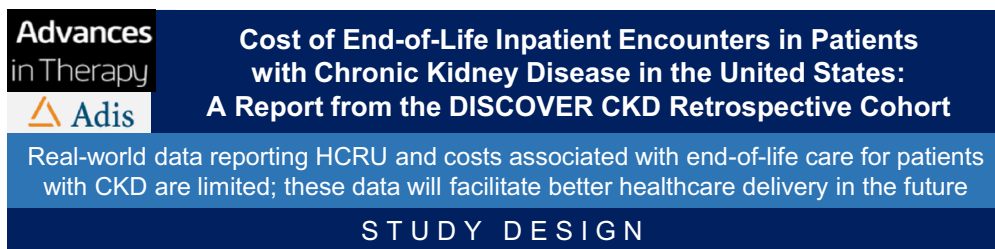

A

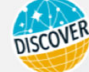

CKD retrospective cohort study

Data source

US Premier Hospital

Database

Jan 2016-Mar 2020
Eligibility criteria

$-\geq 18$ years

$\{\Omega\}$ - ICD-10 code (Stage 3-5

Outcomes

Encounters ending in death

Reason for encounter (ICD-10 code)

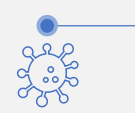

Infection<smiles>c1ccccc1</smiles>

CV

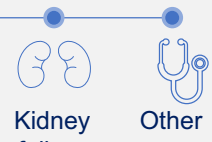

Kidney
failure

$$
\text { CKD/kidney failure) }
$$

Tllat cost and length of hospitalisation per encounter calculated

\section{RESULTS}

\section{7,734}

encounters ending in death

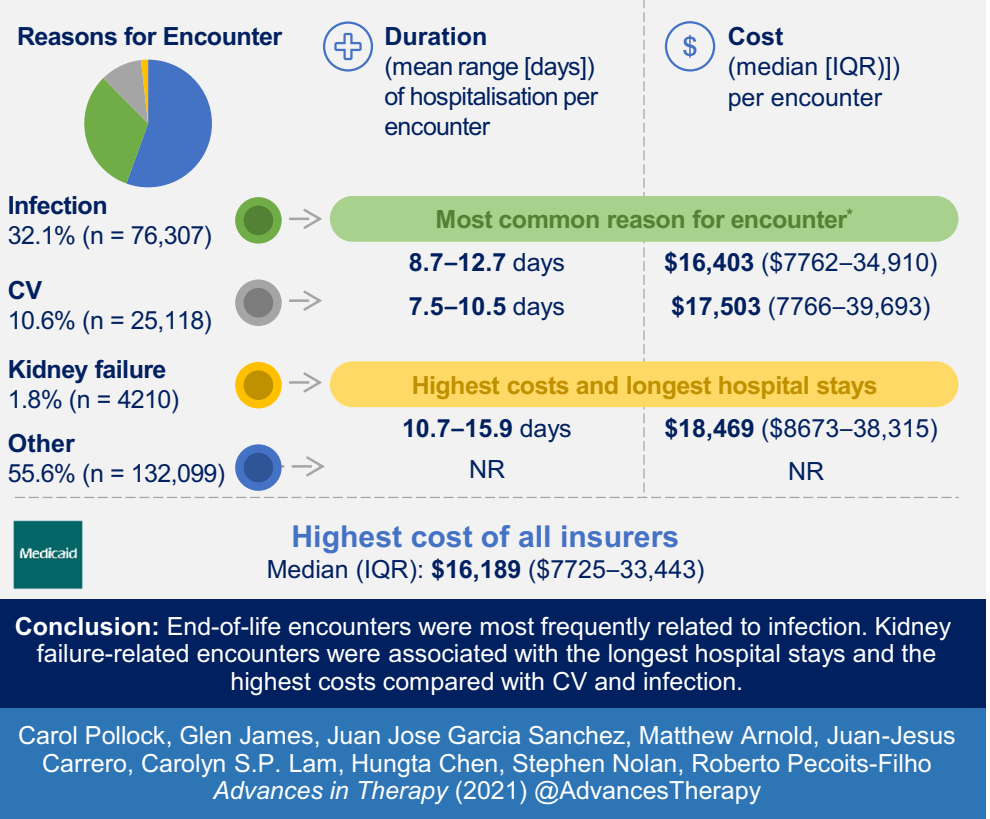

*Among the specific three reasons for encounter assessed. CKD, chronic kidney disease; CV, cardiovascular; ICD-10, international classification of diseases, tenth revision; HCRU, healthcare resource utilisation; IQR, interquartile range; NR, not reported; US, United States. 
Keywords: Chronic kidney disease; Costs; Endof-life; Health economics; Mortality; Retrospective

\section{Key Summary Points}

Why carry out this study?

The global burden of chronic kidney disease (CKD) is substantial and welldocumented; however, there are limited real-world data reporting on healthcare resource utilisation and costs associated with end-of-life care in CKD

A better understanding of the costs associated with end-of-life care in patients with CKD will facilitate better healthcare delivery in the future

This retrospective study used data from inpatient hospital encounters ending in death to evaluate the length of hospitalisation and costs associated with end-of-life care in patients with CKD. Results were stratified according to reasons for death and insurance coverage

What was learned from the study?

Kidney failure-related deaths were associated with the longest hospital stays and the highest costs compared with cardiovascular reasons or infection, thereby emphasising the need for improved CKD management and therapies

Infection was the most frequent cause of death, highlighting the importance of infection prevention and management strategies to delay disease progression

\section{DIGITAL FEATURES}

This article is published with digital features, including a graphical abstract to facilitate

understanding of the article. To view digital features for this article go to https://doi.org/10. 6084/m9.figshare.19078280.

\section{INTRODUCTION}

The global prevalence of chronic kidney disease (CKD) has increased by $29 \%$ since 1990 [1]. Worldwide, the number of individuals with kidney diseases, including CKD (843.6 million), renal replacement therapy (3.9 million) and acute kidney injury (13.3 million) is estimated to exceed 850 million [2]. CKD affects approximately $40 \%$ of adults aged $\geq 60$ years $[3,4]$, and over $80 \%$ of patients with CKD have at least 1 comorbidity $[5,6]$. CKD was the 12 th leading cause of death globally in 2017, an increase compared with past decades [1].

The economic burden of CKD is substantial and increases with disease progression [7-9]. This has been and continues to pose a major challenge for healthcare systems worldwide, particularly during the COVID-19 pandemic [7, 10]. In 2018, spending for patients with CKD (without kidney failure) and for kidney failure accounted for $22.3 \%$ and $7.2 \%$ of the total US Medicare fee-for-service spending, respectively [11].

Many patients with CKD require inpatient care $[12,13]$, which increases with declining kidney function [13-16]. This requires substantial healthcare resource utilisation (HCRU) and costs $[11,17]$. Data reporting on end-of-life care in patients with CKD are limited. In particular, data regarding specific costs for deaths in hospital and how these vary across causes of death and by insurance providers are lacking. Existing studies have focussed on elderly patients with CKD and have reported greater healthcare utilisation compared with other life-limiting illnesses, such as cancer or heart failure. This includes higher rates of hospitalisation, admissions to intensive care units and intensive procedures during the last month of life $[18,19]$. In addition, average spending in the last month of life has also been reported to be approximately five times greater for patients with CKD compared with patients with lung or liver cancer [18]. Despite the significant resource use, end- 
of-life care in CKD may still be suboptimal from a patient perspective. A 2015 report from the Kidney Disease: Improving Global Outcomes (KDIGO) group highlighted end-of-life care for patients with advanced CKD as an area of concern, owing to underutilisation of palliative care and inconsistencies between practices and patients' wishes [20].

Given the need for improvements in planning and delivery of end-of-life care in patients with CKD, contemporary real-world data pertaining to HCRU and costs are required. The focus of the present study was to better understand the real-world hospitalisation burden and costs associated with end-of-life care in the US, using data from the DISCOVER CKD study (ClinicalTrials.gov Identifier: NCT04034992). DISCOVER CKD is a hybrid, multinational, observational cohort study that collects realworld data from patients with CKD [21]. The study aims to provide contemporary real-world insights to inform clinical practice and improve our understanding of the epidemiology, and the clinical and economic burden of CKD. This analysis examined length of hospitalisation and costs associated with end-of-life inpatient encounters by region, reason for the encounter and insurer, using US data from the DISCOVER CKD retrospective cohort.

\section{METHODS}

\section{Data Sources}

This study analysed retrospective data from the DISCOVER CKD retrospective cohort. Data were extracted from the US Premier Hospital Database (PHD, Premier Applied Sciences ${ }^{\circledR}$; Premier Inc.), including data between January 2016 and March 2020. The PHD is a large, US hospitalbased, service-level, all-payer database that contains information on inpatient discharges, including those ending in death, from $>231$ million patients from $>1041$ hospitals and healthcare systems. The patient population included in the PHD is geographically and economically diverse, and a broad range of healthcare facilities are represented, including non-profit, non-governmental and community/ teaching hospitals and health systems. Data available from the PHD include administrative, healthcare utilisation and financial data from patient encounters.

The study protocol followed the principles of the Declaration of Helsinki. All data collection and abstraction were conducted in compliance with the Health Insurance Portability and Accountability Act to ensure patient privacy and confidentiality. The PHD is an anonymised dataset in which no one patient can be individually identified; therefore, no patient consent was required, and the study was exempt from the requirement for Institutional Review Board approval. Only approved persons had access to patient-level data.

\section{Eligibility Criteria}

Eligible patients were aged $\geq 18$ years at first CKD diagnosis code [the International Classification of Diseases, Tenth Revision (ICD-10), indicating CKD stages 3-5 or kidney failure] recorded in the database. The index date was the date of inpatient admission for encounters ending in death. Patients who did not meet these criteria were excluded.

\section{Outcomes}

Inpatient hospital encounters ending in death were identified from patient records with a relevant CKD ICD-10 code and a discharge status of death. Encounters for patients with CKD who had died in hospital were evaluated overall and stratified as cardiovascular (CV) (including coronary heart disease, myocardial infarction and stroke), kidney failure (end-stage renal disease, dependence on renal dialysis or stage 5 CKD with hypertension or heart disease/failure) or infection-related if a corresponding ICD-10 code was recorded as the primary or admitting reason for the encounter (Supplementary Table 1). These three classifications were selected due to their inclusion as frequently reported causes of death in recent CKD outcomes trials [22-24]. Encounters were also classified according to their coverage by commercial, Medicaid, Medicare or other (remaining unclassified or 
unknown) insurers, defined as each patient's first insurer over the hospitalisation period. Length of hospitalisation was calculated for each encounter. Costs of encounters ending in death were calculated as the total HCRU incurred during the encounter, including medical care, medication and procedural costs. All costs were calculated using Instant Health Data (IHD) software (Panalgo, Boston, MA, USA) and inflation-adjusted to 2019 using the Consumer Price Index, published by the US Bureau of Labor Statistics [25].

\section{Statistical Analysis}

All analyses were performed using IHD software and R, version 3.2.1 (R Foundation for Statistical Computing, Vienna, Austria). Data are presented descriptively according to encounter classification and insurer; no between-group statistical comparisons were conducted.

\section{RESULTS}

\section{Patient Disposition and Characteristics}

Among a starting population in the PHD of $4,003,706$ patients with CKD, 3,986,492 patients met the study eligibility criteria. There were 237,734 (6.0\%) inpatient encounters ending in death observed between January 2016 and March 2020 (Fig. 1). Among these encounters, the mean [standard deviation (SD)] age at death was 74.2 (12.4) years, and the proportion of patients who were female and located in the South US region was 45.3 and $45.0 \%$, respectively (Table 1).

Of all encounters, $83.5 \%$ were covered by Medicare insurance, reflecting the advanced age of the study cohort (Table 1). The number of encounters for which the primary reason for inpatient admission was classified as relating to $\mathrm{CV}$ reasons, kidney failure or infection was 25,118, 4,210 and 76,307, respectively (Fig. 1). Characteristics of patients within these groups were consistent with the overall patient population with an outcome of death.

\section{Length of Hospitalisation}

Encounters covered by Medicaid incurred longer hospital stays than encounters covered by other insurers, with a mean (SD) stay of 12.8 (18.4) days. The mean length of hospital stays for encounters covered by commercial, Medicare and other insurance was 11.3 (15.0), 9.1 (11.2) and 10.3 (14.1) days, respectively (Fig. 2). Inpatient encounters related to kidney failure resulted in the most days hospitalised across insurers. The longest hospital stay was covered by Medicaid [mean (SD): 15.9 (21.1) days] (Fig. 2). Hospital stays for infection were longer than for $\mathrm{CV}$ encounters across insurers (mean range, $8.7-12.7$ vs. $7.5-10.5$ days).

\section{Costs of Encounters}

The median [interquartile range (IQR)] total cost of any inpatient encounter was $\$ 17,057$ (\$8040-35,873) (Fig. 3). The median (IQR) costs, stratified by the reason for the encounter, were $\$ 18,469$ (\$8637-38,315) for kidney failure, compared with $\$ 17,503(\$ 7766-39,693)$ for $C V$ and $\$ 16,403(\$ 7762-34,910)$ for infection.

Encounters covered by Medicaid were associated with an overall higher cost than those covered by other insurers, with a median (IQR) value of $\$ 25,692$ ( $\$ 11,568-55,321)$ (Fig. 3). This compares to encounters covered by Medicare where the median (IQR) cost was $\$ 16,189$ (\$7725-33,443) (Fig. 3). When stratified by reason for admission, the highest median (IQR) costs were seen for Medicaid-covered CV-related encounters $(\$ 27,409$ [\$12,291-56,916)]. Mean data for the cost of encounters are presented in Supplementary Table 2 .

\section{DISCUSSION}

This study found that hospitalisation burden and costs associated with end-of-life care in patients with CKD in the US are substantial. In particular, kidney failure-related encounters incurred longer hospital stays and higher costs than either CV or infection-related encounters. Medicaid and Medicare insurance were 


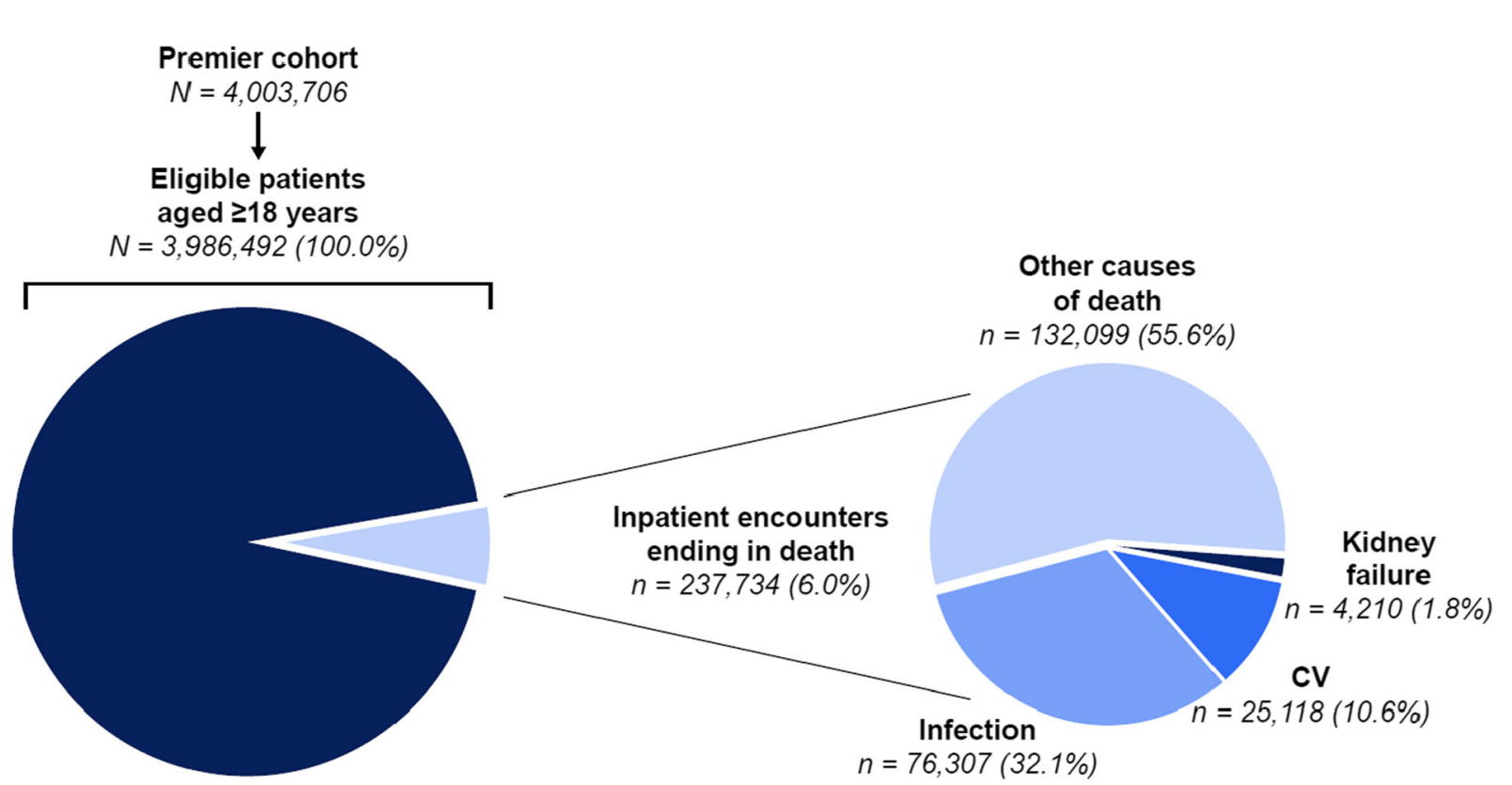

Fig. 1 Encounters within the patient population stratified by principal admitting reason for encounter. $C V$ cardiovascular

Table 1 Patient demographics by inpatient encounter

\begin{tabular}{|c|c|c|c|c|c|}
\hline & \multicolumn{5}{|c|}{ Principal or admitting reason for inpatient encounter that ended in death } \\
\hline & Any reason (total) & Kidney failure & $\mathrm{CV}$ & Infection & Other \\
\hline $\begin{array}{l}\text { Number of deaths, } \\
n \text { (\% of total) }\end{array}$ & 237,734 & $4210(1.8)$ & $25,118(10.6)$ & $76,307(32.1)$ & $132,099(55.6)$ \\
\hline $\begin{array}{l}\text { Age at death, } \\
\text { mean }(S D) \text {, years }\end{array}$ & $74.2(12.4)$ & $71.3(12.6)$ & $74.3(12.1)$ & $73.7(12.5)$ & $\mathrm{N} / \mathrm{A}^{\mathrm{a}}$ \\
\hline Sex, $n(\%)$ & & & & & \\
\hline Female & $107,640(45.3)$ & $1905(45.3)$ & $10,701(42.6)$ & $36,140(47.4)$ & $58,894(24.8)$ \\
\hline US region, $n(\%)$ & & & & & \\
\hline Midwest & $50,414(21.2)$ & $944(22.4)$ & $5150(20.5)$ & $15,821(20.7)$ & $28,499(12.0)$ \\
\hline Northeast & $43,412(18.3)$ & $833(19.8)$ & $4106(16.4)$ & $13,981(18.3)$ & $24,492(10.3)$ \\
\hline South & $106,993(45.0)$ & $1882(44.7)$ & $11,538(45.9)$ & $33,675(44.1)$ & $59,898(25.2)$ \\
\hline West & $36,915(15.5)$ & $551(13.1)$ & $4324(17.2)$ & $12,830(16.8)$ & $19,210(8.1)$ \\
\hline
\end{tabular}

$C V$ cardiovascular, $N / A$ not applicable, $S D$ standard deviation, US United States

${ }^{a}$ These data are not available for this cohort

associated with the highest and lowest overall costs and the longest and shortest length of hospitalisation, respectively.
Among patients in this study, the mean age at death was lower than in the overall US population (74.2 vs. 79.1 years), reflecting the reduced life expectancy with advancing disease 
Any reason $\square$ Kidney failure ${ }^{\mathrm{a}} \quad \mathrm{CV} \square$ Infection

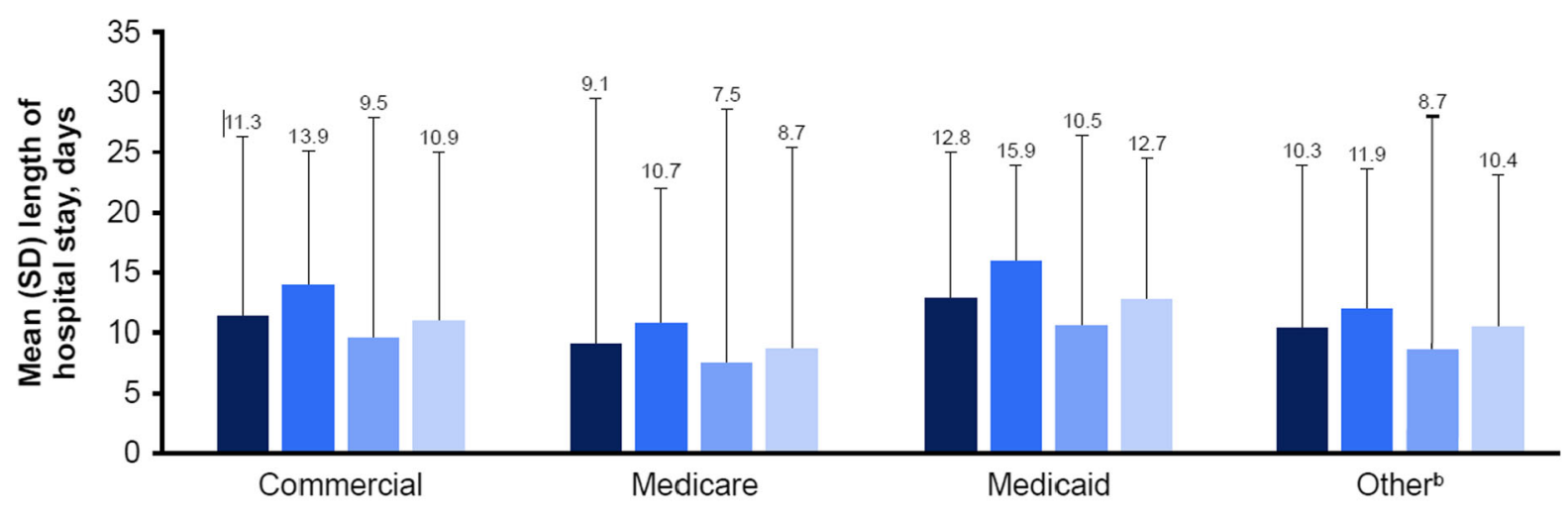

Insurer providing coverage for the encounter

n

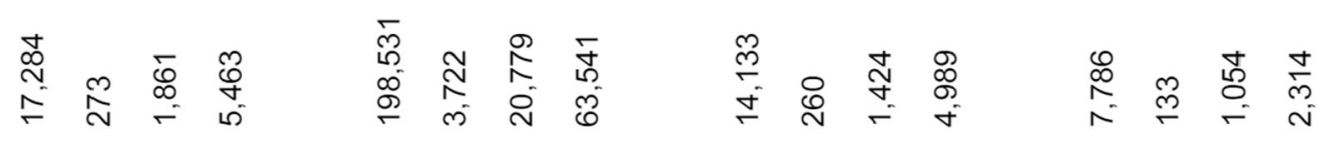

Fig. 2 Mean length of hospital stays by inpatient encounter and insurer. $C V$ cardiovascular, $S D$ standard deviation ${ }^{\text {a Includes }}$ encounters that ended in death attributed to $\mathrm{CKD}$, not necessarily kidney failure ${ }^{\mathrm{b}}$ Insurer unclassified or unknown

Any reason $\square$ Kidney failure $\square \mathrm{CV} \square$ Infection

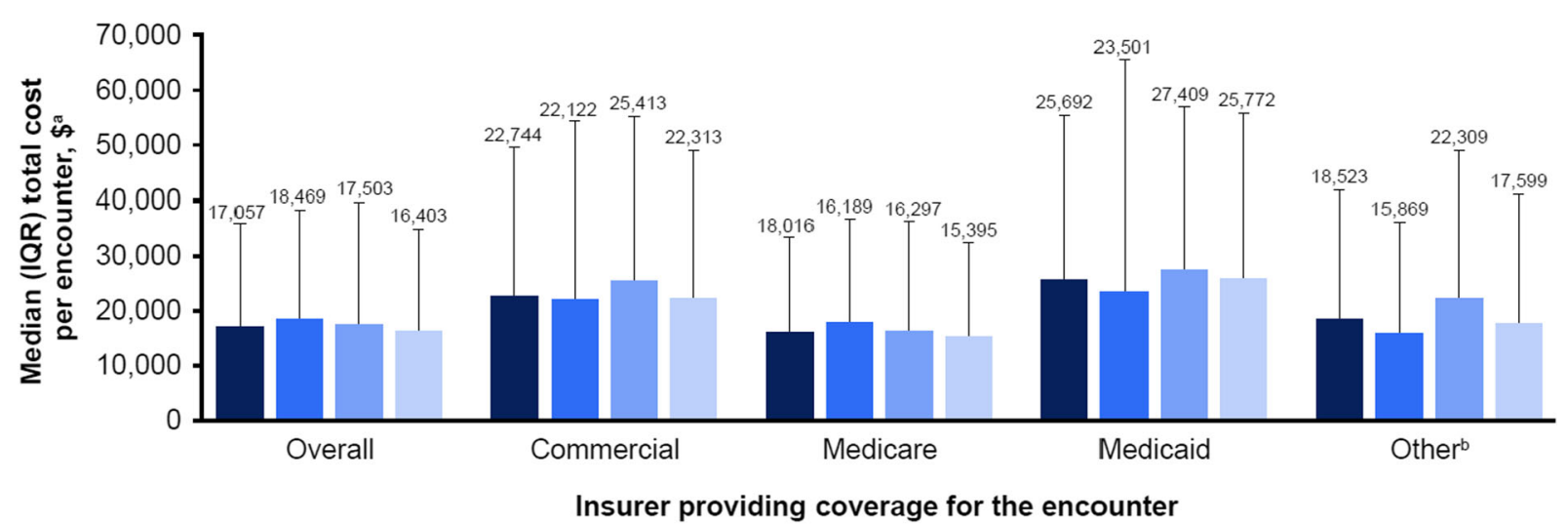

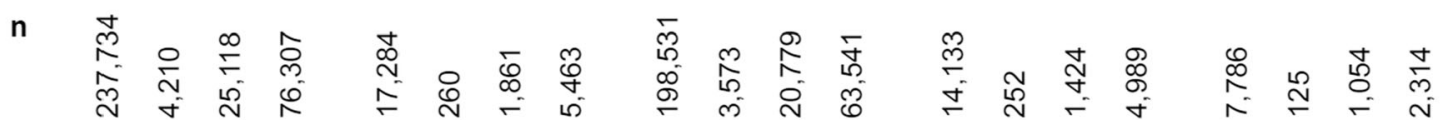

Fig. 3 Median cost per encounter by inpatient encounter and insurer. $C V$ cardiovascular, $I Q R$ interquartile range. ${ }^{\text {as }}$ um of hospital death medical costs and hospital death medication costs for each patient. ${ }^{b}$ Insurer unclassified or unknown

in patients with CKD $[26,27]$. The need for substantial HCRU at the end of life has been reported previously [18-20, 28], and our findings add to this body of evidence. The high costs reported previously and in this study are likely driven by multiple factors, including a requirement for intensive medical resources across multiple specialities (e.g., nursing, nephrology, cardiology and geriatric medicine) at the end of life, increased number of bed-days and costs of treating complications such as infections and other high-risk complications. In addition, factors such as comorbidity burden $[5,6,8,9]$ and complications, which are 
associated with CKD progression and increase the likelihood of premature death [29-31], may contribute to these findings.

In this retrospective study dataset, the most frequently recorded classification for end-of-life encounters was infection, which may reflect characteristics of the included patient population, including a high prevalence of advanced stage CKD. Infection is strongly associated with reduced kidney function and drives CKD progression, leading to an increased requirement for hospitalisation and other healthcare resources [32]. Infection-related hospitalisations have been reported to incur higher medical costs for patients with CKD when compared with patients with preserved renal function, which may be due to longer hospital stays, more frequent ICU admissions and increased severity of infections requiring more costly antibiotics [33]. The advanced age of the study population may also explain the high frequency of infection-related deaths, as patients $>65$ years of age have a significantly higher infection risk than younger patients [32]. Additional factors may include the presence of immunocompromised or comorbid patients in the study population. For example, patients receiving haemodialysis often have an increased infection risk due to predisposing factors, such as weakened immune systems, use of immunosuppressive therapies, frequent use of catheters or needles and increased hospitalisations (providing more opportunity to acquire nosocomial infections) [34-36]. Death secondary to sepsis has been reported to be at least 50-fold higher among patients undergoing haemodialysis than in the general population [37], and the HCRU and costs associated with treating sepsis in an inpatient setting are substantial [38].

These results highlight the importance of preventing infection, as well as early diagnosis and management of infections, to preserve quality of life and delay disease progression in patients with CKD. An additional benefit of preventing infection would be a reduction in end-of-life medical costs; in the US, healthcareacquired infections have been estimated to cost between \$28.4-33.8 billion annually; however, costs could be reduced by an estimated
\$25.0-31.5 billion per year if $70 \%$ of these infections were prevented [39].

Our analysis also showed that CV disease was the second most frequent cause of death, accounting for $10.6 \%$ of inpatient encounters. These findings are corroborated by previous studies which found that between $18-37 \%$ of deaths in patients with CKD were due to $\mathrm{CV}$ disease $[24,40,41]$. The emergence of therapies conferring cardiorenal protection in patients with CKD may help to reduce death from $\mathrm{CV}$ causes among these patients in the future $[22,23,42,43]$. Despite encounters for kidney failure accounting for only $1.8 \%$ of all inpatient encounters resulting in death, they incurred the highest median costs of all encounter types. This finding is corroborated by previous studies which have shown an exponential increase in treatment costs with advancing CKD stage $[7,17]$. Progression from CKD stages $1-2$ to stages $3 a-3 b$ has been associated with a 1.1-1.7fold increase in mean annual costs, whereas progression from stage 3 to stages $4-5$ has been associated with a 1.3-4.2-fold increase in costs [7]. Collectively, these findings emphasise the need for management and therapeutic strategies to prevent or delay progression to kidney failure.

An additional finding from this study was the variation in costs between insurers, with encounters covered by Medicaid and Medicare associated with the highest and lowest costs, respectively. These findings may be attributable to variations between the patient populations covered by each insurer and the terms of the coverage. Most encounters in this study were covered by Medicare, reflecting the advanced age of the study population (US citizens $>65$ years or who require dialysis qualify for Medicare coverage) [44]. Medicare recipients are required to pay part of their treatment costs, which may explain why these encounters were associated with lower costs than those covered by other insurers. In contrast, Medicaid covers patients of all ages, and patients are not usually required to pay any part of their medical expenses [44]. Thus, the higher cost of Medicaid-funded encounters may be because they were fully funded, rather than partially subsidised. 
Although this study focused on inpatient care for patients with CKD, it should be acknowledged that not all patients may want or require this type of treatment, and that conservative management remains an important option for end-of-life care [45]. This approach focuses on slowing the decline in renal function, actively managing symptoms and providing appropriate palliative care in patients who are unlikely to gain benefit from treatments, such as dialysis [45]. Conservative management may be appropriate for certain patients, such as those on dialysis who often experience poor quality of life in their final months [46]. Although patients may opt to die in a hospice rather than in hospital, available data suggest that utilisation of hospice care by patients with CKD on dialysis (haemodialysis or peritoneal dialysis) is low [47-49], with approximately half as many patients with kidney failure utilising hospice care compared with patients at the end of life in the US overall [49]. This is despite evidence that patients in hospice care have better pain control than those who die in hospital [50], as well as survey data suggesting that despite the majority of patients on dialysis dying in acute care facilities, most would prefer to die at home or in a hospice [51]. Hospice care has also been reported to cost less than hospitalisation for dialysis patients, with 1 study reporting cost savings of $\$ 4097$ and $\$ 3020$ in the last 6 months and last week of life, respectively, compared with hospitalisation [49]. Taken together, improving palliative care for patients with CKD is likely to confer benefits in terms of both cost and quality of life, with the potential for cost savings to be invested in preventive strategies for CKD.

Strengths of this study include the use of a large, generalisable claims database from the US, representing $\sim 20 \%$ of US inpatient discharges among private and academic hospitals. Limitations include those inherent to database analyses, such as the potential for missing data, under coding of nonbillable events and use of ICD codes to select and classify patients, which may lead to misclassification or under reporting of events. In particular, the potential for misclassification of primary versus secondary causes of death cannot be excluded, given that secondary causes of death were not assessed in this study. Only data on in-hospital encounters were available, meaning that the costs associated with CKD and death from CKD occurring in other settings could not be considered. This may limit the generalisability of these findings to the broader US population. Additionally, patient characteristics were not reported and so could not be used to explore reasons for the high proportion of infection-related deaths; causes of death were classified according to the primary diagnosis upon hospital admission, whereas the precise drivers of death are likely to be multifactorial. Further to this, data stratified by CKD stage were not available, which would have enabled a more granular assessment of costs. Finally, characteristics of hospitals included in the PHD may differ from other hospitals, given that they submit data for the purpose of quality improvement. This may limit the ability to generalise the results from this analysis to other US hospitals.

\section{CONCLUSIONS}

KDIGO recommendations for end-of-life care focus on the provision of individualised and high-quality care that meets patients' needs and preferences. In this analysis of US patients with $\mathrm{CKD}$, infection was most frequently related to end-of-life encounters. Relatively few encounters were associated with kidney failure, but these incurred the highest cost and required greater HCRU than encounters for other reasons. These novel findings highlight the importance of strategies for delaying CKD progression, managing complications and optimising resource allocation for at-risk patient groups to improve the quality of end-of-life care for patients and their families.

\section{ACKNOWLEDGEMENTS}

The authors thank Alyshah Abdul Sultan for his contributions to the study design and analysis. 
Funding. The DISCOVER CKD study and all associated publication costs, including the journal's Rapid Service and Open Access Fees, were funded by AstraZeneca.

Medical Writing and Editorial Assistance. Medical writing support was provided by Katie Webster and editorial support was provided by Rachael Cazaly, both of Core, Knutsford, UK, supported by AstraZeneca according to Good Publication Practice guidelines (https:// www.acpjournals.org/doi/10.7326/M15-0288).

Authorship. All named authors meet the International Committee of Medical Journal Editors (ICMJE) criteria for authorship for this article, take responsibility for the integrity of work and have given their approval for this version to be published.

Authors' Contributions. Glen James, Juan Jose Garcia Sanchez, Matthew Arnold, Stephen Nolan and Hungta Chen were involved in the study design, data collection and analysis. All authors contributed to the development of the manuscript, including reviewing, providing feedback and approving the final version of the submitted manuscript.

Prior Presentation. The data included in this manuscript was presented as a poster at the World Congress of Nephrology Virtual Meeting (15-18 April 2021).

Disclosures. Juan Jose Garcia Sanchez, Matthew Arnold, Stephen Nolan and Hungta Chen are employees and stockholders of AstraZeneca. Glen James was an employee and stockholder of AstraZeneca at the time of manuscript preparation. Juan-Jesus Carrero reports institutional grants from AstraZeneca, Vifor Pharma and Astellas; speaker fees from AstraZeneca, Abbott and Nutricia; and consultancy for AstraZeneca, Baxter Healthcare and Bayer. Carolyn S.P. Lam is supported by a Clinician Scientist Award from the National Medical Research Council of Singapore; has received research support from Boston Scientific, Bayer, Roche Diagnostics, AstraZeneca, Medtronic and Vifor Pharma; has served as consultant or on the Advisory Board/
Steering Committee/Executive Committee for Abbott Diagnostics, Amgen, Applied Therapeutics, AstraZeneca, Bayer, Biofourmis, Boehringer Ingelheim, Boston Scientific, Corvia Medical, Cytokinetics, Darma Inc., Eko.ai Pte Ltd., JanaCare, Janssen Research \& Development LLC, Medtronic, Menarini Group, Merck, MyoKardia, Novartis, Novo Nordisk, Radcliffe Group Ltd., Roche Diagnostics, Sanofi, Stealth BioTherapeutics, The Corpus, Vifor Pharma and WebMD Global LLC; and serves as co-founder and nonexecutive director of Us2.ai Pte Ltd. Carol Pollock reports Advisory Board membership for AstraZeneca, Vifor, Eli Lilly and Boehringer Ingelheim; as well as speaker fees for Novartis, Janssen Cilag, Otsuka, AstraZeneca and Vifor Pharma. Roberto Pecoits-Filho is an employee of Arbor Research Collaborative for Health, which receives global support for the ongoing DOPPS Programs (provided without restriction on publications by a variety of funders - for details see https://www.dopps.org/AboutUs/Support.aspx). He also reports grants from Fresenius Medical Care, nonfinancial support from AstraZeneca, Bayer, Boehringer, Novo Nordisk, Akebia and FibroGen; as well as personal fees from Retrophin and consulting fees from George Clinical outside the submitted work.

Compliance with Ethics Guidelines. The study protocol followed the principles of the Declaration of Helsinki. All data collection and abstraction were conducted in compliance with the Health Insurance Portability and Accountability Act to ensure patient privacy and confidentiality. The PHD is an anonymised dataset in which no one patient can be individually identified; therefore, no patient consent was required, and the study was exempt from the requirement for Institutional Review Board approval. Only approved persons had access to patient-level data.

Data Availability. The datasets generated and/or analysed during the current study are available upon reasonable request in accordance with AstraZeneca's data sharing policy described at https://astrazenecagroup-dt.pharmacm. com/DT/Home. 
Open Access. This article is licensed under a Creative Commons Attribution-NonCommercial 4.0 International License, which permits any non-commercial use, sharing, adaptation, distribution and reproduction in any medium or format, as long as you give appropriate credit to the original author(s) and the source, provide a link to the Creative Commons licence, and indicate if changes were made. The images or other third party material in this article are included in the article's Creative Commons licence, unless indicated otherwise in a credit line to the material. If material is not included in the article's Creative Commons licence and your intended use is not permitted by statutory regulation or exceeds the permitted use, you will need to obtain permission directly from the copyright holder. To view a copy of this licence, visit http://creativecommons.org/licenses/by$\mathrm{nc} / 4.0 /$.

\section{REFERENCES}

1. GBD Chronic Kidney Disease Collaboration. Global, Regional, and National Burden of Chronic Kidney Disease, 1990-2017: A systematic analysis for the global burden of disease study 2017. Lancet (Lond, Engl). 2020;395:709-33.

2. Jager KJ, Kovesdy C, Langham R, et al. A single number for advocacy and communication-worldwide more than 850 million individuals have kidney diseases. Nephrol Dial Transpl: official publication of the European Dialysis and Transplant Association- European Renal Association. 2019;34:1803-5.

3. Stevens LA, Viswanathan G, Weiner DE. Chronic kidney disease and end-stage renal disease in the elderly population: current prevalence, future projections, and clinical significance. Adv Chronic Kidney Dis. 2010;17:293-301.

4. Mallappallil M, Friedman EA, Delano BG, McFarlane SI, Salifu MO. Chronic kidney disease in the elderly: evaluation and management. Clin Pract (Lond). 2014;11:525-35.

5. MacRae C, Mercer SW, Guthrie B, Henderson D. Comorbidity in chronic kidney disease: a large cross-sectional study of prevalence in scottish primary care. Br J Gen Pract. 2021;71:e243-e9.
6. Lee WC, Lee YT, Li LC, et al. The number of comorbidities predicts renal outcomes in patients with stage 3-5 chronic kidney disease. J Clin Med. 2018;7:pii:E493.

7. Elshahat S, Cockwell P, Maxwell AP, et al. The impact of chronic kidney disease on developed countries from a health economics perspective: a systematic scoping review. PLoS ONE. 2020;15: e0230512.

8. Kerr M, Matthews B, Medcalf JF, O'Donoghue D. End-of-life care for people with chronic kidney disease: cause of death, place of death and hospital costs. Nephrol Dial Transpl: official publication of the European Dialysis and Transplant AssociationEuropean Renal Association. 2017;32:1504-9.

9. Manns B, Hemmelgarn B, Tonelli M, et al. The cost of care for people with chronic kidney disease. Can J Kidney Health Dis. 2019;6:2054358119835521.

10. Tan X, Chen G, Yuan F, Liu Y, Liu H. Inflated cost burden of hemodialysis during COVID-19 pandemic. Blood Purif. 2021;10.1159/000513699:1-2. https://doi.org/10.1159/000513699.

11. United States Renal Data System. 2020 USRDS Annual Data Report, CKD. 2020. https://adr.usrds. org/2020/chronic-kidney-disease. Accessed 10 Jun 2021.

12. Khan SS, Kazmi WH, Abichandani R, et al. Health care utilization among patients with chronic kidney disease. Kidney Int. 2002;62:229-36.

13. Schrauben SJ, Chen HY, Lin E, et al. Hospitalizations among adults with chronic kidney disease in the United States: a cohort study. PLoS Med. 2020;17:e1003470.

14. Go AS, Chertow GM, Fan D, McCulloch CE, Hsu $\mathrm{CY}$. Chronic kidney disease and the risks of death, cardiovascular events, and hospitalization. N Engl J Med. 2004;351:1296-305.

15. Alexander M, Bradbury BD, Kewalramani R, et al. Chronic kidney disease and US healthcare resource utilization in a nationally representative sample. Am J Nephrol. 2009;29:473-82.

16. Mix TC, St peter WL, Ebben J, et al. Hospitalization during advancing chronic kidney disease. Am J Kidney Dis: the official journal of the National Kidney Foundation. 2003;42:972-81.

17. Golestaneh L, Alvarez PJ, Reaven NL, et al. All-cause costs increase exponentially with increased chronic kidney disease stage. Am J Manag Care. 2017;23: S163-72. 
18. Chen B, Fan VY, Chou YJ, Kuo CC. Costs of care at the end of life among elderly patients with chronic kidney disease: patterns and predictors in a nationwide Cohort study. BMC Nephrol. 2017;18: 36.

19. Wong S, Kreuter W, O'Hare A. Treatment intensity at the end of life in older adults receiving long-term dialysis. Arch Intern Med. 2012;172:661-3.

20. Yan S, Kwan YH, Thumboo J, Low LL. Characteristics and health care utilization of different segments of a multiethnic Asian population in Singapore. JAMA Netw Open. 2019;2:e1910878.

21. Pecoits-Filho R, James G, Carrero JJ, et al. Methods and rationale of the DISCOVER CKD global observational study. Clin Kidney J. 2021;14:1570-8.

22. Perkovic V, Jardine MJ, Neal B, et al. Canagliflozin and renal outcomes in Type 2 diabetes and nephropathy. N Engl J Med. 2019;380:2295-306.

23. Bakris GL, Agarwal R, Anker SD, et al. Effect of finerenone on chronic kidney disease outcomes in type 2 diabetes. N Engl J Med. 2020;383:2219-29.

24. Heerspink HJL, Sjostrom CD, Jongs N, et al. Effects of dapagliflozin on mortality in patients with chronic kidney disease: a pre-specified analysis from the DAPA-CKD randomized controlled trial. Eur Heart J. 2021;42:1216-27.

25. US Bureau of Labor Statistics. Consumer Price Index. 2021. https://www.bls.gov/cpi/. Accessed 10 Jul 2021.

26. Turin TC, Tonelli M, Manns BJ, et al. Chronic kidney disease and life expectancy. Nephrol Dial Transpl: official publication of the European Dialysis and Transplant Association- European Renal Association. 2012;27:3182-6.

27. World of Meters. Life Expectancy by Country and in the World. 2021. https://www.worldometers. info/demographics/life-expectancy/. Accessed Jul 2021.

28. Kerr M, Bray B, Medcalf J, O'Donoghue DJ, Matthews B. Estimating the financial cost of chronic kidney disease to the NHS in England. Nephrol Dial Transpl: official publication of the European Dialysis and Transplant Association- European Renal Association. 2012;27(Suppl 3):iii73-80.

29. Mu F, Betts KA, Woolley JM, et al. Prevalence and economic burden of hyperkalemia in the united states medicare population. Curr Med Res Opin. 2020;36:1333-41.
30. Stauffer ME, Fan T. Prevalence of anemia in chronic kidney disease in the United States. PLoS ONE. 2014;9:e84943.

31. Webster AC, Nagler EV, Morton RL, Masson P. Chronic kidney disease. Lancet (Lond, Engl). 2017;389:1238-52.

32. Chang $\mathrm{CH}$, Fan PC, Kuo G, et al. Infection in advanced chronic kidney disease and subsequent adverse outcomes after dialysis initiation: a nationwide cohort study. Sci Rep. 2020;10:2938.

33. Su G, Xu H, Marrone G, et al. Chronic kidney disease is associated with poorer in-hospital outcomes in patients hospitalized with infections: electronic record analysis from China. Sci Rep. 2017;7:11530.

34. Abbasi SH, Aftab RA, Chua SS. Risk factors associated with nosocomial infections among end stage renal disease patients undergoing hemodialysis: a systematic review. PLoS ONE. 2020;15:e0234376.

35. Centers for disease control and prevention. Dialysis safety. 2020. https://www.cdc.gov/dialysis/index. html. Accessed Jul 2021.

36. Collier S, Davenport A. Reducing the risk of infection in end-stage kidney failure patients treated by dialysis. Nephrol Dial Transpl: official publication of the European Dialysis and Transplant Association- European Renal Association. 2014;29: 2158-61.

37. Sarnak MJ, Jaber BL. Mortality caused by sepsis in patients with end-stage renal disease compared with the general population. Kidney Int. 2000;58: 1758-64.

38. Paoli CJ, Reynolds MA, Sinha M, Gitlin M, Crouser E. Epidemiology and costs of sepsis in the United States-an analysis based on timing of diagnosis and severity level. Crit Care Med. 2018;46:1889-97.

39. RD Scott. The direct medical costs of healthcareassociated infections in US hospitals and the benefits of prevention. 2009. https://stacks.cdc.gov/ view/cdc/11550. Accessed Jul 2021.

40. Thompson S, James M, Wiebe $\mathrm{N}$, et al. Cause of death in patients with reduced kidney function. J Am Soc Nephrol. 2015;26:2504-11.

41. Mok Y, Matsushita K, Sang Y, et al. Association of kidney disease measures with cause-specific mortality: the Korean Heart study. PLoS ONE. 2016;11: e0153429.

42. Heerspink HJL, Stefansson BV, Correa-Rotter R, et al. Dapagliflozin in patients with chronic kidney disease. N Engl J Med. 2020;383:1436-46. 
43. Filippatos G, Anker SD, Agarwal R, et al. Finerenone and cardiovascular outcomes in patients with chronic kidney disease and type 2 diabetes. Circulation. 2021;143:540-52.

44. US Department of Health and Human Services. What is the difference between Medicare and Medicaid? 2015. https://www.hhs.gov/answers/ medicare-and-medicaid/what-is-the-differencebetween-medicare-medicaid/index.html. Accessed Jul 2021.

45. KDIGO. CKDIGO 2012 Clinical practice guideline for the evaluation and management of chronic kidney disease. Kidney Int Suppl. 2012;3:1-150.

46. Murtagh FE, Addington-Hall J, Edmonds P, et al. Symptoms in the month before death for stage 5 chronic kidney disease patients managed without dialysis. J Pain Symptom Manag. 2010;40:342-52.

47. United States Renal Data System. 2020 USRDS Annual Data Report, ESRD. 2020. https://adr.usrds. org/2020/end-stage-renal-disease. Accessed 10 Jun 2021.

48. Chiang JK, Chen JS, Kao YH. Comparison of medical outcomes and health care costs at the end of life between dialysis patients with and without cancer: a national population-based study. BMC Nephrol. 2019;20:265.

49. Murray AM, Arko C, Chen SC, Gilbertson DT, Moss $\mathrm{AH}$. Use of hospice in the United States dialysis population. Clin J Am Soc Nephrol. 2006;1: 1248-55.

50. Cohen LM, Germain M, Poppel DM, Woods A, Kjellstrand CM. Dialysis discontinuation and palliative care. Am J Kidney Dis: the official journal of the National Kidney Foundation. 2000;36:140-4.

51. Davison SN. End-of-life care preferences and needs: perceptions of patients with chronic kidney disease. Clin J Am Soc Nephrol. 2010;5:195-204. 